\title{
Finite Element Based Comparative Analysis of Positive Streamers in Multi Dispersed Nanoparticle Based Transformer Oil
}

\author{
Mihir Bhatt ${ }^{1, *}$, Praghnesh Bhatt ${ }^{2}$ \\ ${ }^{1}$ Department of Electrical Engineering, Chandubhai S Patel Institute of Technology, Charotar University of \\ Science and Technology, Changa, India \\ ${ }^{2}$ Department of Electrical Engineering, Pandit Deendayal Energy University, Gandhinagar, India \\ Received 16 May 2021; received in revised form 08 July 2021; accepted 09 July 2021 \\ DOI: https://doi.org/10.46604/ijeti.2021.7681
}

\begin{abstract}
The dispersion of dissimilar nanoparticles (NPs) in transformer oil (TO) has a major impact on fast propagating positive streamers. This work investigates the positive streamer dynamics in TO modified by dispersing both $\mathrm{Fe}_{3} \mathrm{O}_{4}$ and $\mathrm{Al}_{2} \mathrm{O}_{3}$ NPs at a homogenous concentration. The hydrodynamic drift diffusion model of positive streamer evolution and propagation are solved using the commercial software package COMSOL Multiphysics. The impact of multiple NPs (MNPs) has been analysed for streamer propagation, electric field intensity, electron density, and space charge density of modified TO. MNPs successfully reduce streamer propagation velocity by $50 \%, 17 \%$, and $37.5 \%$ comparing to pure oil, $\mathrm{Fe}_{3} \mathrm{O}_{4}$ based nanodielectric fluids (NDFs), and $\mathrm{Al}_{2} \mathrm{O}_{3}$ based NDFs, respectively. The spatial distribution of electron density reveals the loss of electrons from the ionization region until the saturation of NPs. A comparative study demonstrates that MNPs significantly alter the streamer dynamics and augment the dielectric strength of TO compared to individual NPs.
\end{abstract}

Keywords: transformer oil, multi-nanoparticles, hybrid nanofluid, positive streamer

\section{Introduction}

Power transformer is one of the most important electrical equipment for providing reliable energy flow that contributes to the highest capital investments for an electric utility in project executions. The critical conditions such as the overvoltage caused by lightning or switching surges can severely damage the power transformers, which in turn lead to power supply interruption in larger portion of power systems.

The healthy and reliable operation of power transformer primarily relies on an effective insulation system. Mineral oil (MO) is the most substantial element of the transformer that provides the reliability and safety against the transient overvoltages and enhances the service lifespan of power transformers. Apart from heat transfer capability, MO possesses excellent electrical properties, but the polycyclic aromatic hydrocarbons diluted in it may explode the transformer when subjected to intensive thermal, mechanical, and electrical stresses [1].

In recent time, the dielectric and thermal properties of vegetable oils or natural esters have been considered a potential alternative to the existing petroleum oil. However, they are unable to provide required cooling and insulating features as compared to MO. Moreover, with the increase in service life, the vegetable oil based paper insulation is prone to severe thermal aging due to rigorous electrical and thermal stresses [1]. The heating of the existing liquid dielectric emits the dissolved gases such as carbon monoxide $(\mathrm{CO})$, methane $\left(\mathrm{CH}_{4}\right)$, ethane $\left(\mathrm{C}_{2} \mathrm{H}_{6}\right)$, acetylene $\left(\mathrm{C}_{2} \mathrm{H}_{2}\right)$, ethylene $\left(\mathrm{C}_{2} \mathrm{H}_{4}\right)$, etc., which are very harmful to the human health and environment.

* Corresponding author. E-mail address: mihirbhatt.ee@ charusat.ac.in 
The emerging advancements in new age nanotechnology have opened up new opportunities to overcome the limitations of conventional liquid insulations. The names "nanofluid (NF)" and "nano-liquid" are employed alternatively to express transformer oil (TO) / nanoparticle (NP) combination for electrical isolation and chilling purposes. The particles (single or multiple) with nano scaled dimensions (usually $<100 \mathrm{~nm}$ ) suspended with smaller percentage proportion in TO result in NF, which was first produced at the Argonne National Laboratory [1].

NPs have wide-spread application in different engineering branches like electrical, electronic, civil, mechanical, biotechnology, biomedical, automobile, and space engineering. Dielectric strength (DS) of the insulating liquid is one of the most important factors in determining the reliability and durability of a transformer. It has been observed that the individual suspension of NPs can effectively slow down the streamer velocity and amplify the DS of the liquid dielectrics [1-2].

In ionized liquid, NPs act as a trapping agent to adsorb electrons from the ionized space, which reduce streamer velocity and enhance DS. The dielectric properties of liquid insulation are greatly dependent on the size, type, concentration, shape, and surface modifiers of NPs. Low concentration of large sized NPs trap lesser electrons from the ionized space that reduces the DS of NFs. Moreover, the properties of dissimilar NPs also affect the electrical performance of NFs. The higher the electrical conductivity is, the lower the relaxation time constant will be. This allows rapid absorption of electrons and hinders the streamer progression [3].

Moreover, the optimum size and concentration of individual NPs (INPs) can effectively enhance both electrical and thermophysical properties of the carrier oil. However, in many cases, the properties of NF prepared by individual suspension fail to meet all the required specifications. The higher concentration of NPs causes the agglomeration that tends to reduce both electrical and heat transfer capacities of career oil. The larger size of NPs may help in reducing the streamer growth due to high electrical conductivity, but oppositely it will increase the dielectric losses and hence the heat traits.

Hence, there is a strong need for alternate solution to obtain superior electrical and thermal characteristic of NFs. Emerging nanotechnology has now come up with an alternate solution to the nanodielectric fluids (NDFs) prepared via single NPs. The term "hybrid nanofluid (HNF)" is collaboratively named to express the TO modified by dispersing two or more nanostructured particles of unlike properties either in a combination or merged form [4-5]. The foremost need of manufacturing multi-NP based dielectric fluid is to obtain the augmented electrical and thermophysical properties at smaller density without the loss of properties at high density of INPs.

The major objectives of this study are outlined below:

(1) To examine positive streamer dynamics in TO modified by a mixture of $\mathrm{Fe}_{3} \mathrm{O}_{4}$ and $\mathrm{Al}_{2} \mathrm{O}_{3}$ NPs, a model in COMSOL Multiphysics is developed. A two-dimensional axisymmetric fluid model is established with the needle-plane electrode configuration poured in multiple NP (MNP) based TO.

(2) The growth of two dimensional positive streamers in MNP based TO is compared with MO and modified MO by each INP.

(3) The effects of dispersing two NPs with different properties on streamer velocity, electric field intensity, electron density, and space charge density in a fluid are investigated.

\section{Literature Review}

Properties of different NPs have been verified experimentally so far and they are classified into three main categories as follows [1-2]:

(1) Conducting NPs: $\mathrm{Fe}_{3} \mathrm{O}_{4}, \mathrm{Fe}_{2} \mathrm{O}_{3}, \mathrm{ZnO}$, and $\mathrm{SiC}$

(2) Semiconducting NPs: $\mathrm{TiO}_{2}, \mathrm{CuO}, \mathrm{Cu}_{2} \mathrm{O}$, and $\mathrm{CdS}$

(3) Dielectric NPs: $\mathrm{Al}_{2} \mathrm{O}_{3}, \mathrm{SiO}_{2}$, and $\mathrm{BN}$ 
The effect of shallow trap on positive streamer growth in mono-dispersed NF was investigated by Zhou et al. [3]. The surface modified $\mathrm{Fe}_{3} \mathrm{O}_{4}, \mathrm{TiO}_{2}$, and $\mathrm{Al}_{2} \mathrm{O}_{3}$ NPs with identical shape, size, and concentration were chosen for the study. The

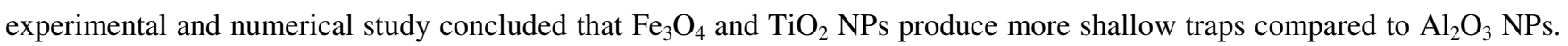
The more the shallow traps are, the higher the dissipation of electrons is, due to the repeated trapping and de-trapping process. This will reduce the electric field strength at the head of the streamer and increase the DS of single NP based NFs (SNFs). Dispersed NPs, however, increase the unfavorable dielectric losses in comparison to MO. Moreover, no such footprints are available regarding the nature of traps in NFs.

An effectiveness of different NPs on breakdown and pre-breakdown characteristics under positive impulse voltage was studied by Chen et al. [6]. $\mathrm{Fe}_{3} \mathrm{O}_{4}$ and $\mathrm{TiO}_{2} \mathrm{NPs}$ decrease the velocity of the streamer by around $52 \%$ as compared to pure oil. No clear evidence has been discussed on mechanism by which the streamer velocity is reduced.

Sima et al. [7] have investigated experimentally and analytically the influence of $\mathrm{Fe}_{3} \mathrm{O}_{4}, \mathrm{TiO}_{2}$, and $\mathrm{Al}_{2} \mathrm{O}_{3} \mathrm{NPs}$ on positive streamer discharge. It is found that $\mathrm{Fe}_{3} \mathrm{O}_{4}$ NPs performed better as compared to other NPs. Compared to the base oil, the breakdown voltage (BDV) increases to $44.3 \%, 33.3 \%$, and $35.5 \%$ for $\mathrm{Fe}_{3} \mathrm{O}_{4}, \mathrm{Al}_{2} \mathrm{O}_{3}$, and $\mathrm{TiO}_{2}$ based NDFs respectively. The potential well produced by the induced or polarized charges traps the electrons and hinders the streamer acceleration. The effect of NP's properties, i.e., shape, size, concentration, etc., was not studied.

Volume fractions of NPs influence streamer propagation in NDFs and improve DS significantly. Wang et al. [8] have conducted experiments to observe the effect of dissimilar NPs on insulating properties of NDFs at 5\% to $40 \%$ concentration. They found that $\mathrm{Al}_{2} \mathrm{O}_{3}$ is more superior than $\mathrm{Fe}_{3} \mathrm{O}_{4}$ and $\mathrm{TiO}_{2} \mathrm{NPs}$. Moreover, studies revealed that the dielectric performance gets deteriorated with the increase in the concentration of NPs.

Yadav et al. [9] have manufactured the TO based NF by dispersing different volume fractions (10\%, 20\%, 30\%, and 40\%) of $\mathrm{Fe}_{3} \mathrm{O}_{4}$ NPs to investigate DS. They have noticed that 20\% (optimal) concentration of magnetite improves DS by $34 \%$ compared to the base liquid. DS shows the worst results when the concentration is increased to $40 \%$. The similar study was done numerically by Rodríguez-Serna et al. [10].

The charging time constant of NPs plays a vital role in streamer dynamics. Velasco et al. [11] have investigated the influence of NP's charging time constant on positive streamer progression numerically. The numerical analysis reveals that the NPs with shorter charging time constant can effectively increase the streamer transmission time and reduce local ionization. Contradictory, long charging time will slow down the rate of electron absorption from the ionization zone. This will allow streamer to elongate rapidly.

The type of NPs and its relevant electrical properties such as electrical conductivity and permittivity have significant effect on both positive and negative streamer dynamics. The high electrical conductivity of NPs offers extremely low relaxation time constant compared to streamer propagation time constant. The higher the electrical conductivity is, the lower the relaxation time constant will be, which traps the electrons very quickly and hinders the streamer transmission velocity [12-13]. The dispersion of NPs can augment the positive streamer inception voltage, but it has proven less efficacy towards the negative streamer dynamics [14]. A detailed review report on potential application of TO based NDFs are available in [1-2].

In early 2020s, a heat transfer characteristics and fluidity of HNFs in parabolic trough solar collector under turbulent flow were investigated by Ekiciler et al. [15]. Silver $(\mathrm{Ag})$, zinc oxide $(\mathrm{ZnO})$, titanium dioxide $\left(\mathrm{TiO}_{2}\right)$, and magnesium oxide $(\mathrm{MnO})$ NPs were chosen to prepare HNFs. Both thermal efficiency and heat transfer performance significantly increase when the base fluid (syltherm 800) was modified by two dissimilar NPs at different volume fractions.

Ekiciler [16] has prepared a HNF comprising a mixture of titanium dioxide, copper, and ethylene glycol to numerically inspect the heat transfer characteristics and fluidity in a duct with a triangular rib. The comparisons were made with pure ethylene glycol and the base fluid modified by INPs. The numerical study shows that the HNF behaves better than the other types of fluids for the same application. 
The alternating current (AC) DS of $\mathrm{TiO}_{2} / \mathrm{Al}_{2} \mathrm{O}_{3} / \mathrm{MoS}_{2}$ based $\mathrm{HNF}$ with sixteen different combinations was investigated by Sumathi et al. [17]. The optimum volume concentration of $0.094 \%$ for $\mathrm{Al}_{2} \mathrm{O}_{3}, 0.014 \%$ for $\mathrm{TiO}_{2}$, and $0.097 \%$ for $\mathrm{MoS}_{2}$ can enrich the DS of HNF 7.7 and 3.7 times more than pure TO and magnetic NF respectively [17]. In 2017, Ghadikolaei et al. [18] have investigated the thermophysical properties of $\mathrm{TiO}_{2}-\mathrm{Cu}$ /water based HNFs. Runge-Kutta Fehlberg method was used to investigate the effect of induced magnetic field on thermophysical properties of a prepared HNF [18].

Aberoumand and Jafarimoghaddam [19] have prepared a HNF by suspending two dissimilar NPs (silver and $\mathrm{WO}_{3}$ ). They have investigated the thermal conductivity and DS of modified TO at different volume fractions. The experiment shows that the dispersion of two dissimilar NPs in TO enhances the thermal conductivity by $41 \%$ at higher concentration than INP based fluid. Contradictory, the DS of HNF shows poor performance compared to base fluid. The possible reason for achieving the reduction in DS was the electrical conductivity of silver NPs [19].

Thabet et al. [20] have compared the enhancement achieved in electrical conductivity for the TO modified by single and multiple $\mathrm{NPs}_{(}\left(\mathrm{SiO}_{2}, \mathrm{ZnO}, \mathrm{TiO}_{2}\right.$, and graphite). The study was carried out at different concentration and temperature ranges. The dispersion at high weight percentage gives rise to both static and electrophoretic conductivity that lead to the increase in electrical conductivity. The increase in electrical conductivity can effectively reduce the NP relaxation time constant (the rate at which the NP can absorb the electrons from the ionized space). This will help in reducing the streamer propagation and rising the DS [20-21].

Qing et al. [22] have prepared a $\mathrm{HNF}$ by dispersing $\mathrm{SiO}_{2}$ and graphene NPs to investigate thermal conductivity and electrical properties of naphthenic MO after the modification. The coating of $\mathrm{SiO}_{2} \mathrm{NPs}$ over the graphene NPs effectively maintains the excellent thermal conductivity of graphene NPs. Furthermore, the insulating nature of $\mathrm{SiO}_{2}$ hinders the increase in electrical conductivity of graphene NPs. It has also been noticed that the thermal conductivity increases with the increase in temperature and concentration of graphene NPs. Moreover, the viscosity of HNFs is found to be higher than the pure oil, but decreases with the increase in temperature due to the rise in Brownian motion [22].

Mansour et al. [23] have investigated the thermal and dielectric properties of hybrid TO based NFs. More than $10 \%$ reduction was observed in BDV when TO was modified by dispersing barium titanate (BT) NPs. BDV was improved when $0.01 \mathrm{~g} / \mathrm{L}$ of metal oxide particles were added to the NF prepared by $0.005 \mathrm{~g} / \mathrm{L}$ of BT NPs. The experiment reveals that DS was

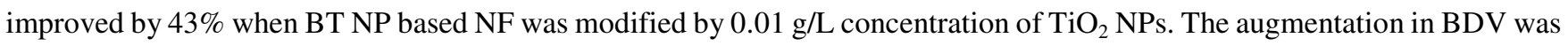
achieved only when $\mathrm{TiO}_{2}$ and $\mathrm{SiO}_{2}$ NPs were dispersed. The adverse effect was observed with $\mathrm{Al}_{2} \mathrm{O}_{3}$ based HNFs [23-24].

Thabet et al. [25] have made an effort to investigate the influence of MNPs on positive streamer propagation in silicone oil and vegetable oil. They found that MNP based fluid can effectively slow down the streamer velocity due to the absorption of a large number of electrons at limited time frame compared to INPs [25]. The silicon oil may not be the alternative because of its high viscosity at high temperatures and limited biodegradability.

From the literature survey, it is clear that MNPs extensively improve both thermal and electrical performance of TO [26-27]. It is observed that less efforts have been devoted to investigate the pre-breakdown stages in TO modified by MNPs. The pre-breakdown stages of liquid dielectrics involve the generation and propagation of streamer discharge, which is a complex phenomenon to understand. The presence of sparking channels leads to catastrophic failure of the transformers due to the involvement of rapid ionization under heavy electrical, mechanical, and thermal stresses. The fast propagating positive streamers are considered to be more severe than slowly developed negative streamer. The work reported in literature so far revealed that the streamer is propagating faster in MO due to high electron density and space charges when positive impulse voltage is applied. NPs have a great influence on the generation of such charge carriers that may lead to the breakdown in SNFs and HNFs. 


\section{Materials and Methods}

Various techniques are used to characterize NPs' morphology, size, crystalline structure, conductive nature, etc. To figure out NPs' crystalline structure, nature of phase, and grain size, x-ray diffraction (XRD) is widely used. Uniform size and shape of concentrated NPs can be analyzed via transmission electron microscope (TEM). TEM may produce misleading images due to orientation effects. The surface conditions of NPs can be analyzed by scanning electron microscope (SEM). TEM creates images by transmitting the electrons whereas SEM creates images by the reflected electrons. The detailed review for different NP characterization techniques is available in [28].

BDV (AC, direct current (DC), and impulse), resistivity, permittivity, electrical conductivity, and dissipation factor are the key electrical properties of any dielectric fluids. The AC DS of NFs can be determined by oil BDV test kit as per IEC 60156 $[18,24]$. Marx impulse voltage generator is the widely used equipment to produce both lightning and switching overvoltages to determine the impulse voltage strength of NFs. Pi-Max3, a high speed intensified charge coupled device (ICCD) camera, captures the streamer shadowgraph images to study the streamer behaviors in early stages of breakdown [3-4]. Electrical conductivity, permittivity, and dissipation factor can be determined from the results of resistance and capacitance measurement by parallel LCR meters during the test [23].

\subsection{Charging dynamics of MNPs}

Prior to develop a mathematical model, it is required to understand the charging dynamics of MNPs dispersed in TO. Fig. 1 shows that how MNPs are charged when exposed to an external excitation. The NPs of dissimilar properties are subjected to intensive electric field (Fig. 1 (a)) that allows the charging of NPs. The induction and the polarization play a key role in accumulating the charges on two opposite sides of conducting and insulative NPs respectively (Fig. 1 (b)).

As shown in Fig. 1(c), the positively charged hemisphere of NP quickly absorbs the electron produced due to ionization of TO. The process of absorbing electrons from the surrounding ionized liquid space is continued till the positive hemisphere of NPs becomes negatively charged and saturates (Fig. 1(d)). Once the NPs saturate, they will reject the absorption of the electrons from the surrounding ionized region. Due to the charging of MNPs, more electrons will be absorbed than INPs. This slows down the rate of ionization and hence the streamer velocity compared to the SNFs and pure oils.

The effectiveness of NPs to attract free electrons from the ionized space strongly depends upon the density of charges available on their surfaces. The surface charge concentration for the multiple conducting and insulative/semi-conducting NPs are determined by Eq. (1) and Eq. (2), respectively [21, 25]. The surface charge density for two dissimilar NPs can be obtained from Eq. (3) [21, 25].

$$
\begin{aligned}
& \mathrm{Q}_{\text {multi-cond. }}=3 \mathrm{~K}_{1} \mathrm{E}_{0} \cos \theta \\
& \mathrm{Q}_{\text {multi(diele./semi-cond. })}=3 \varepsilon_{1} \mathrm{E}_{0} \cos \theta\left[\sum_{n=1}^{k}\left(\frac{\varepsilon_{n+1}-\varepsilon_{1}}{2 \varepsilon_{1}+\varepsilon_{n+1}}\right)\right] \\
& \mathrm{Q}_{\text {cond.-diele. }}=3 \varepsilon_{1} \mathrm{E}_{0} \cos \theta\left[\sum_{n=1}^{k}\left(\frac{\varepsilon_{n+1}-\varepsilon_{1}}{2 \varepsilon_{1}+\varepsilon_{n+1}}\right)+m\right]
\end{aligned}
$$

where $\theta$ is the angle of negative charges on positive hemisphere of conductive, dielectric, or semi-conductive NPs. 


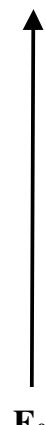

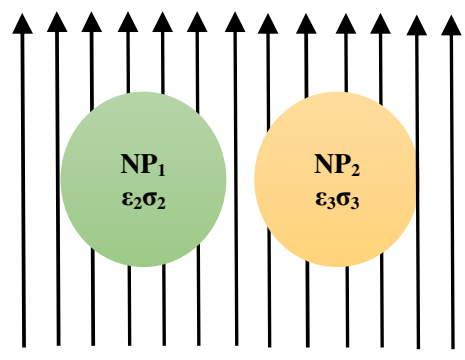

(a) The NPs exposed to heavy electric field

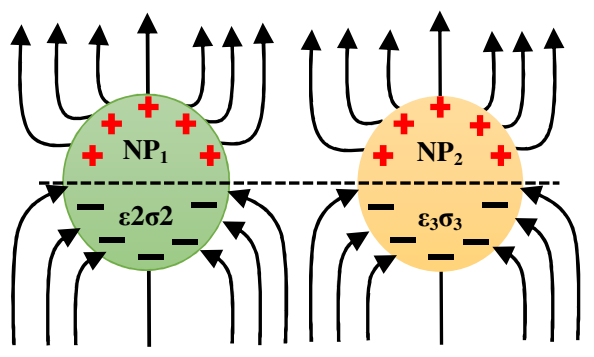

(b) Charge accumulation on two opposite surfaces

$\mathbf{E}_{\mathbf{0}}$

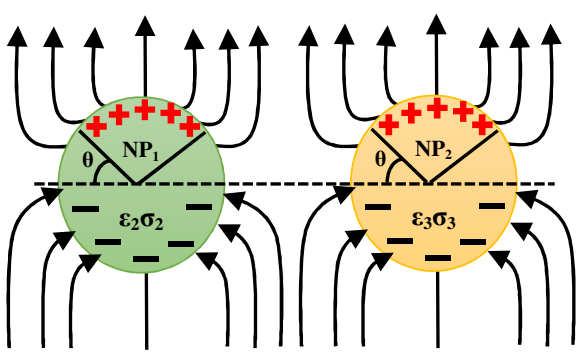

(c) Electron absorption by NPs
Transformer Oil

$\varepsilon_{1} \sigma_{1}$

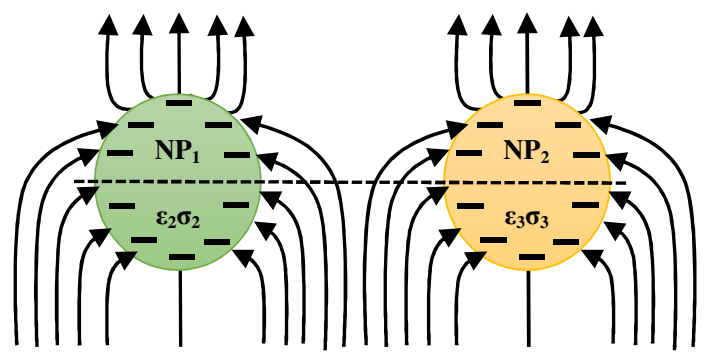

(d) Saturation of NPs

Fig. 1 Charging dynamics of MNPs in TO under heavy electric field [21, 25]

The saturation charge for the fluid containing multiple conducting NPs can be determined from Eq. (4), however, Eq. (5) is used for multiple insulative or semi-conducting NPs. Eq. (6) determines the saturation charge for the fluid containing NPs of dissimilar properties [21, 25].

$$
\begin{aligned}
& \mathrm{Q}_{s}=-12 \pi \varepsilon_{1} \mathrm{E}_{0} \sum_{n=1}^{m}\left(R_{n}^{2}\right) \\
& \mathrm{Q}_{s}=-12 \pi \varepsilon_{1} \mathrm{E}_{0} \sum_{j=1}^{k}\left[\left(R_{j+1}\right)^{2} \times\left(\frac{\varepsilon_{j+1}-\varepsilon_{1}}{2 \varepsilon_{1}+\varepsilon_{j+1}}\right)\right] \\
& \mathrm{Q}_{s}=-12 \pi \varepsilon_{1} \mathrm{E}_{0}\left\{\sum_{j=1}^{k}\left[\left(R_{j+1}\right)^{2} \times\left(\frac{\varepsilon_{j+1}-\varepsilon_{1}}{2 \varepsilon_{1}+\varepsilon_{j+1}}\right)\right]+\sum_{n=1}^{m} R_{n}{ }^{2}\right\}
\end{aligned}
$$

The charging of nanostructured particles performs a key role in enriching the dielectric properties of conventional TO. The effectiveness of this process entirely depends upon the relaxation time constant that allows NPs to absorb or trap the free running electrons from the ionized space until they get saturated. The advantage of absorbing the electrons reduces the net space charge density, net electron density, electric field strength, and velocity of the streamer. In this study, $\mathrm{Fe}_{3} \mathrm{O}_{4}$ and $\mathrm{Al}_{2} \mathrm{O}_{3} \mathrm{NPs}_{\text {are }}$ considered. Table 1 shows the magnitude of saturation charge and number of electrons absorbed by individual $\mathrm{Fe}_{3} \mathrm{O}_{4}, \mathrm{Al}_{2} \mathrm{O}_{3}$, and mixed NPs.

From Table 1, it can be seen that each $\mathrm{Al}_{2} \mathrm{O}_{3}$ and $\mathrm{Fe}_{3} \mathrm{O}_{4}$ NPs can absorb approximately 8 and 11 electrons after which they will saturate and stop absorbing electrons from the ionized space; whereas the mixture of NPs absorbs more electrons (18e) from the ionizing region and effectively reduces further progression of streamer until the voltage magnitude is increased. It is found that the dispersion of NPs reduces the density of electrons to a great extent compared to the base oil until they become saturated.

Table 1 Saturation charge and number of the absorbed electrons

\begin{tabular}{|c|c|c|c|}
\hline Type of $\mathrm{NP}$ & Magnitude of $\mathrm{Q}_{s}(\mathrm{C})$ & Number of electrons & Charge relaxation time constant \\
\hline Individual $\mathrm{Al}_{2} \mathrm{O}_{3}$ & $1.270 \mathrm{E}-18$ & $7.9 \mathrm{e}$ & $42.5 \mathrm{~s}$ \\
\hline Individual $\mathrm{Fe}_{3} \mathrm{O}_{4}$ & $1.836 \mathrm{E}-18$ & $11.4 \mathrm{e}$ & $7.47 \mathrm{E}-14 \mathrm{~s}$ \\
\hline Mixture of $\mathrm{Fe}_{3} \mathrm{O}_{4}$ and $\mathrm{Al}_{2} \mathrm{O}_{3}$ & $2.83 \mathrm{E}-18$ & $18 \mathrm{e}$ & $2.01 \mathrm{E}-14 \mathrm{~s}$ \\
\hline
\end{tabular}




\subsection{Modelling of positive streamer propagation in MNP based TO}

Nowadays, in addition with the experimental procedures, various finite element based commercial softwares have been adopted to study the streamer dynamics in high voltage insulations. COMSOL Multiphysics is one of the widely used commercial softwares because of its flexibility to the users for coupling the multiple physics [4-5, 9-11]. In this study, a hydrodynamic drift diffusion model of TO based $\mathrm{HNF}$ is developed considering spherical $\mathrm{Fe}_{3} \mathrm{O}_{4}$ and $\mathrm{Al}_{2} \mathrm{O}_{3} \mathrm{NPs}$ with identical weight (10 grams) and diameter $(10 \mathrm{~nm})$. A 2D axisymmetric model with needle-plane geometry, as shown in Fig. 2, is developed to analyze the streamer dynamics in HNF. The distance of separation between two electrodes is kept as $1 \mathrm{~mm}$. The curvature radius of needle is chosen to be $40 \mu \mathrm{m}$ respectively.

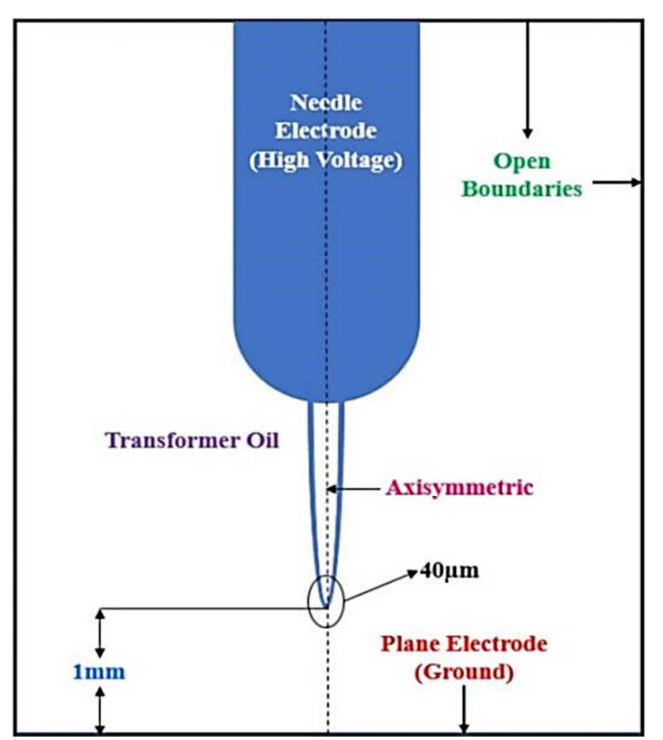

Fig. 2 Needle-plane geometry of simulation in TO [5]

The boundary conditions for the simulation are set as follows [10]:

(1) The boundary condition at plane electrode is set to zero potential whereas the needle electrode potential is set to double exponential impulse voltage equation.

(2) The boundary conditions at the electrode surfaces are set to convective fluxes for all the species to represent the charge continuity equations at electrodes.

(3) The outer boundaries, i.e., other than the electrodes, are set to zero flux for all species.

Tables 2 and 3 show the parameters and electrical properties of TO and NPs chosen for simulation, respectively.

Table 2 Parameters of TO [9-11]

\begin{tabular}{|c|c|c|c|}
\hline Parameter & Symbol & Value & SI unit \\
\hline Ionization potential & $\Delta$ & 7.1 & $\mathrm{eV}$ \\
\hline Intermolecular distance & $\alpha$ & $3 \mathrm{E}-10$ & $\mathrm{~m}$ \\
\hline Electron charge & $q$ & $-1.602 \mathrm{E}-19$ & $\mathrm{C}$ \\
\hline Electron mass & $m^{*}$ & $9.1 \mathrm{E}-32$ & $\mathrm{~kg}$ \\
\hline Recombination rates & $R_{p e}, R_{p n}$ & $1.645 \mathrm{E}-17$ & $\mathrm{~m}^{3} / \mathrm{s}$ \\
\hline Mobility of ions & $\mu_{n}, \mu_{p}$ & $1 \mathrm{E}-9$ & $\mathrm{~m}^{2} / \mathrm{V} / \mathrm{s}$ \\
\hline Electron mobility & $\mu_{e}$ & $1 \mathrm{E}-4$ & $\mathrm{~m}^{2} / \mathrm{V} / \mathrm{s}$ \\
\hline Specific heat capacity & $C_{v}$ & 1700 & $\mathrm{~J} / \mathrm{kg} / \mathrm{K}$ \\
\hline Density of oil & $\rho_{l}$ & 880 & $\mathrm{~kg} / \mathrm{m}^{3}$ \\
\hline Thermal conductivity & $k_{T}$ & 0.13 & $\mathrm{~W} / \mathrm{m} /{ }^{\circ} \mathrm{K}$ \\
\hline Electron attachment time constant & $\tau_{a}$ & 200 & $\mathrm{~ns}$ \\
\hline Permittivity & $\varepsilon$ & $2.2 \varepsilon_{0}$ & - \\
\hline Planck's constant & $h$ & $6.63 \mathrm{E}-34$ & $\mathrm{~m}^{2} \mathrm{~kg} / \mathrm{s}$ \\
\hline
\end{tabular}


Table 3 Electrical properties of NPs [5-6]

\begin{tabular}{|c|c|c|c|c|}
\hline \multirow{2}{*}{ Property } & \multirow{2}{*}{ Symbol } & \multicolumn{2}{|c|}{ Material } & \multirow{2}{*}{$\begin{array}{c}\text { SI } \\
\text { unit }\end{array}$} \\
\cline { 3 - 4 } & & $\mathrm{Fe}_{3} \mathrm{O}_{4}$ & $\mathrm{Al}_{2} \mathrm{O}_{3}$ & \\
\hline Charge relaxation time constant & $\tau_{n p}$ & $7.47 \mathrm{E}-14$ & 42.5 & $\mathrm{~s}$ \\
\hline Permittivity & $\varepsilon_{n p}$ & $80 \varepsilon 0$ & $9.9 \varepsilon 0$ & $\mathrm{~F} / \mathrm{m}$ \\
\hline Electrical conductivity & $\sigma_{n p}$ & $1 \mathrm{E} 4$ & $1 \mathrm{E}-12$ & $\mathrm{~S} / \mathrm{m}$ \\
\hline
\end{tabular}

\subsection{Mathematical modelling of HNFs}

Streamer formation in liquid dielectrics results in breakdown due to the atomic disintegration caused by the space charges. During this process, electrons, cations, and anions will be produced, accelerated, and lost. In this study, a HNF is modelled by choosing the conducting $\left(\mathrm{Fe}_{3} \mathrm{O}_{4}\right)$ and insulating $\left(\mathrm{Al}_{2} \mathrm{O}_{3}\right)$ NPs with equal weight in TO to investigate its effect on positive streamer propagation. In the first process, $\mathrm{NF}$ is modelled by dispersing $\mathrm{Fe}_{3} \mathrm{O}_{4} \mathrm{NPs}$ in $\mathrm{TO}$ which then modified by $\mathrm{Al}_{2} \mathrm{O}_{3} \mathrm{NPs}_{\text {. }}$ No matter which type of NP is dispersed first, it will not affect the dynamics of the streamer, since its volume is distinct from NP size.

The charge carrier continuity and Poisson's equations need to be modified to account for MNPs. The following equations represent the modelling of HNFs for the streamer progression.

$$
\begin{aligned}
& \frac{\partial \rho_{p}}{\partial t}+\nabla \cdot\left(\rho_{p} \mu_{p} \vec{E}\right)=G_{I}(|\vec{E}|)+\frac{\rho_{p} \rho_{e} R_{p e}}{q}+\frac{\rho_{p}\left(\rho_{n}+\rho_{n p 1}+\rho_{n p 2}\right) R_{p n}}{q} \\
& \frac{\partial \rho_{e}}{\partial t}-\nabla \cdot\left(\rho_{e} \mu_{e} \vec{E}\right)=-G_{I}(|\vec{E}|)-\frac{\rho_{p} \rho_{e} R_{p e}}{q}-\frac{\rho_{e}}{\tau_{a}}-\frac{\rho_{e}}{\tau_{n p 1}}\left[1-\mathrm{H}\left(\rho_{n p s a t 1}-\rho_{n p 1}\right)\right]-\frac{\rho_{e}}{\tau_{n p 2}}\left[1-\mathrm{H}\left(\rho_{n p s a t 2}-\rho_{n p 2}\right)\right] \\
& \frac{\partial \rho_{n}}{\partial t}-\nabla \cdot\left(\rho_{n} \mu_{n} \vec{E}\right)=\frac{\rho_{e}}{\tau_{a}}-\frac{\rho_{p} \rho_{n} R_{p n}}{q} \\
& \frac{\partial \rho_{n p 1}}{\partial t}-\nabla \cdot\left(\rho_{n p 1} \mu_{n p 1} \vec{E}\right)=\frac{\rho_{e}}{\tau_{n p 1}}\left[1-\mathrm{H}\left(\rho_{n p s a t 1}-\rho_{n p 1}\right)\right]-\frac{\rho_{p} \rho_{n p 1} R_{p n}}{q} \\
& \frac{\partial \rho_{n p 2}}{\partial t}-\nabla \cdot\left(\rho_{n p 2} \mu_{n p 2} \vec{E}\right)=\frac{\rho_{e}}{\tau_{n p 2}}\left[1-\mathrm{H}\left(\rho_{n p s a t 2}-\rho_{n p 2}\right)\right]-\frac{\rho_{p} \rho_{n p 2} R_{p n}}{q} \\
& \nabla \cdot\left(\varepsilon_{0} \varepsilon_{r} \vec{E}\right)=\rho_{p}+\rho_{n}+\rho_{e}+\rho_{n p 1}+\rho_{n p 2}
\end{aligned}
$$

Because of the generation of charge carriers, the temperature of the oil increases. Eq. (13) shows the dissipation of heat due to Joule's heating.

$$
\frac{\partial T}{\partial t}+\vec{v} \cdot \nabla \mathrm{T}=\frac{1}{\rho_{l} C_{v}}\left(\mathrm{k}_{T} \nabla^{2} \mathrm{~T}+\vec{E} \cdot \vec{J}\right)
$$

where

$$
\vec{J}=\left(\rho_{p} \mu_{p}-\rho_{e} \mu_{e}-\rho_{n} \mu_{n}-\rho_{n p 1} \mu_{n p 1}-\rho_{n p 2} \mu_{n p 2}\right) \vec{E}
$$

The thermal conductivity, density, and specific heat capacity of HNFs can be calculated from Table 4 . 
Table 4 Equations to model the thermal properties of HNF [18]

\begin{tabular}{|c|c|}
\hline Property & Equation \\
\hline Thermal conductivity & $\frac{k_{h n f}}{k_{s n f}}=\frac{k_{n p 2}+2 k_{s n f}-2 \varphi_{n p 2}\left(k_{s n f}-k_{n p 2}\right)}{k_{n p 2}+2 k_{s n f}+\varphi_{n p 2}\left(k_{s n f}-k_{n p 2}\right)} ; \frac{k_{s n f}}{k_{M O}}=\frac{k_{n p 1}+2 k_{M O}-2 \varphi_{n p 1}\left(k_{M O}-k_{n p 1}\right)}{k_{n p 1}+2 k_{M O}+\varphi_{n p 1}\left(k_{M O}-k_{n p 1}\right)}$ \\
\hline Density & $\rho_{h n f}=(1-\varphi) \rho_{b f}+\varphi \rho_{h n p}$ \\
\hline Specific heat capacity & $C_{P h n f}=(1-\varphi) C_{P b f}+\varphi C_{P h n p}$ \\
\hline
\end{tabular}

The volume concentration can be computed by [27]:

$$
\varphi=\frac{\frac{w_{\mathrm{Fe}_{3} \mathrm{O}_{4}+\mathrm{Al}_{2} \mathrm{O}_{3}}}{\rho_{\mathrm{Fe}_{3} \mathrm{O}_{4}+\mathrm{Al} \mathrm{I}_{2} \mathrm{O}_{3}}}}{\frac{w_{\mathrm{Fe}_{3} \mathrm{O}_{4}+\mathrm{Al}_{2} \mathrm{O}_{3}}}{\rho_{\mathrm{Fe}_{3} \mathrm{O}_{4}+\mathrm{Al}_{2} \mathrm{O}_{3}}}+\frac{w_{\text {oil }}}{\rho_{\text {oil }}}} \times 100 \%
$$

The density of hybrid nanoparticles (HNPs) can be determined by [27]:

$$
\left(\rho_{\mathrm{Fe}_{3} \mathrm{O}_{4}+\mathrm{Al}_{2} \mathrm{O}_{3}}\right)_{p}=\frac{\left(\rho_{\mathrm{Fe}_{3} \mathrm{O}_{4}} \times w_{\mathrm{Fe}_{3} \mathrm{O}_{4}}\right)+\left(\rho_{\mathrm{Al}_{3} \mathrm{O}_{3}} \times w_{\mathrm{Al}_{2} \mathrm{O}_{3}}\right)}{w_{\mathrm{Fe}_{3} \mathrm{O}_{4}}+w_{\mathrm{Al}_{2} \mathrm{O}_{3}}}
$$

The specific heat capacity of HNPs can be calculated by [27]:

$$
\left(C_{p, F e_{3} \mathrm{O}_{4}+\mathrm{Al}_{2} \mathrm{O}_{3}}\right)_{p}=\frac{\left(C_{p, F e_{3} \mathrm{O}_{4}} \times w_{\mathrm{Fe}_{3} \mathrm{O}_{4}}\right)+\left(C_{p, \mathrm{Al}_{2} \mathrm{O}_{3}} \times w_{\mathrm{Al}_{2} \mathrm{O}_{3}}\right)}{w_{\mathrm{Fe}_{3} \mathrm{O}_{4}}+w_{\mathrm{Al}_{2} \mathrm{O}_{3}}}
$$

\section{Results and Discussion}

The ionization plays a vital role in producing the electronic avalanche that causes electrical breakdown in liquid dielectrics. Under the application of high voltage stress, the electric field is strongly enhanced at the tip of needle electrode due to its extremely low diameter ( $40 \mu \mathrm{m}$ in this study). Electrons are injected from the electrode tip due to this enhanced electric field as the electrode's work function is eliminated. The work function is the binding energy that is required to prevent the evaporation of the electron from its surface. The injected weightless electrons gain enough kinetic energy from the applied heavy potential and collide with neutral atom of insulating liquid.

The bombardment of electrons with neutral atoms will cause molecular structure of a neutral particle to deform mechanically that liberate more electrons and positive ions simultaneously. The involvement of ionization mechanisms such as collision, photo-ionization, positive ion bombardment, ionization due to meta-stable/excited atoms, and electron attachment produces more highly mobile electrons and heavier positive and negative ions. Due to the negligible mass, the electrons transport quickly into the ionization zone by keeping behind the heavier positive ions close to the needle electrode. These positive ions weaken the local electric field at needle tip, whereas the energetic electrons enhance the electric field at the front of the ionized zone that encourages the streamer channel to elongate towards the ground electrode.

To investigate the influence of INPs and MNPs on positive streamer dynamics, a double exponential voltage $\left(\mathrm{V}_{i}\right)$ of positive polarity is applied to the needle electrode. Eq. (18) describes a unidirectional double exponential voltage wave, where $\tau_{1}$ and $\tau_{2}$ are two exponential functions which generates impulse voltage as per IEC60060-1 [29].

$$
\mathrm{V}_{i}=\mathrm{KV}_{0}\left(e^{-t / \tau_{1}}-e^{-t / \tau_{2}}\right)
$$

where $\mathrm{K}$ is the compensation factor to achieve the peak value of a generated impulse voltage. 


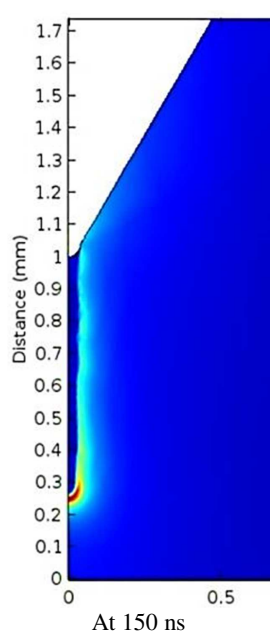

(a) Mineral oil

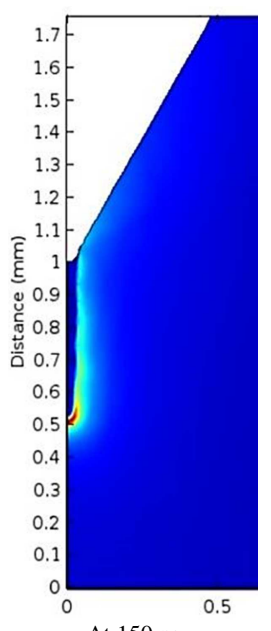

(c) $\mathrm{Fe}_{3} \mathrm{O}_{4}$ based $\mathrm{NF}$
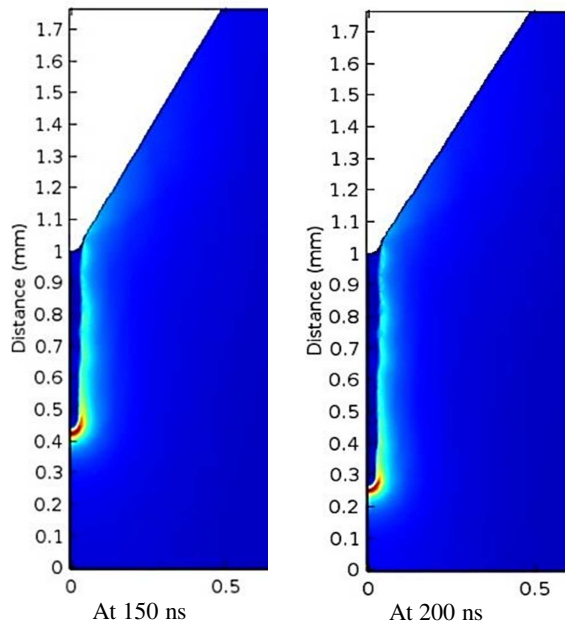

(b) $\mathrm{Al}_{2} \mathrm{O}_{3}$ based $\mathrm{NF}$
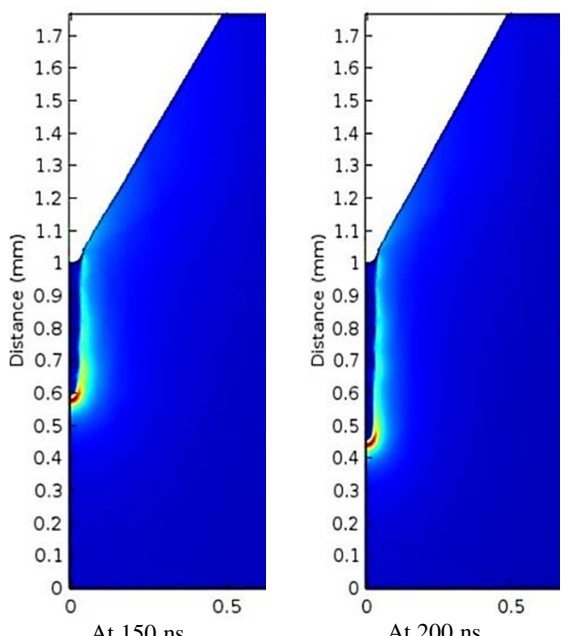

(d) $\mathrm{Fe}_{3} \mathrm{O}_{4}+\mathrm{Al}_{2} \mathrm{O}_{3}$ based $\mathrm{HNF}$

Fig. $32 \mathrm{D}$ positive streamer evolution under application of $+90 \mathrm{kV}$ impulse voltage with 50 ns rise time

Fig. 3 shows a comparison of positive streamer evolution and its propagation in MO and modified MO. It is noticed that the streamer accelerates faster in unmodified TO, whereas it takes more time to hit the plane electrode when modified by INPs and MNPs. It is noted from Fig. 3 that the maximum electric field does not stay at the needle tip but moves gradually towards the ground electrode due to the rise in ionization rate. The electric field wave approaches the plane electrode at $200 \mathrm{~ns}$ when TO is not modified by NPs. The streamer will take more time to hit the ground electrode when the base oil is modified by the individual and two dissimilar NPs.

The average velocity at which the streamer is accelerating in pure TO is approximately $5.0 \mathrm{~km} / \mathrm{s}$. The average velocities of streamer in $\mathrm{TO}$ with individual $\mathrm{Al}_{2} \mathrm{O}_{3}$ and $\mathrm{Fe}_{3} \mathrm{O}_{4} \mathrm{NPs}$ are close to $4.0 \mathrm{~km} / \mathrm{s}$ and $3.0 \mathrm{~km} / \mathrm{s}$ respectively. The physical dimensions and results obtained are well in agreement with [7]. The promising reduction has achieved in streamer propagation for the TO containing the mixture of two dissimilar NPs. The streamer is accelerating with an average velocity of $2.5 \mathrm{~km} / \mathrm{s}$ when TO contains a mixture of $\mathrm{Al}_{2} \mathrm{O}_{3}$ and $\mathrm{Fe}_{3} \mathrm{O}_{4}$ NPs with an identical concentration.

Fig. 4 shows a comparative analysis of positive streamer propagation length, electric field strength, net space charge density, and electron density respectively. From Fig. 4(a), it is observed that the dispersion of MNPs can effectively reduce the streamer length or the velocity compared to the base oil and the NDFs containing INPs. The rate of reduction in velocity can be explained based on both charge relaxation and polarization theories for the dielectric fluid containing both conducting and insulative NPs. Due to the extremely low charge relaxation time constant of $\mathrm{Fe}_{3} \mathrm{O}_{4}$ particles, the electrons are quickly absorbed 
from the surrounding ionized space. That converts high speed electrons into slow negative ions and reduces the propagation velocity of the streamer. On the other hand, the polarization of $\mathrm{Al}_{2} \mathrm{O}_{3}$ particles produces the potential well over its surface, which traps the electrons and slows down the speed of an electric field wave. The results are in accordance with [7, 12].

Fig. 4(b) shows the impact of dispersed NPs as an individual and mixture on the magnitude of electric field intensity that is responsible for the streamer evolution and its propagation. The charging dynamics of NPs explains the reduction in the magnitude of electric field intensity in modified insulating liquids. As discussed in section 3, the NPs adsorb the electrons from the vicinity of the ionization space until they get saturated. In this study, NPs' charging time is considered to be 20 ns. It is clearly depicted from Fig. 4(b) that HNF can effectively reduce the intensity of an electric field wave due to the adsorption of more electrons from the ionized space compared to both MO and SNFs. The insufficient electric field strength prevents more electrons from developing and hinders the streamer propagation.

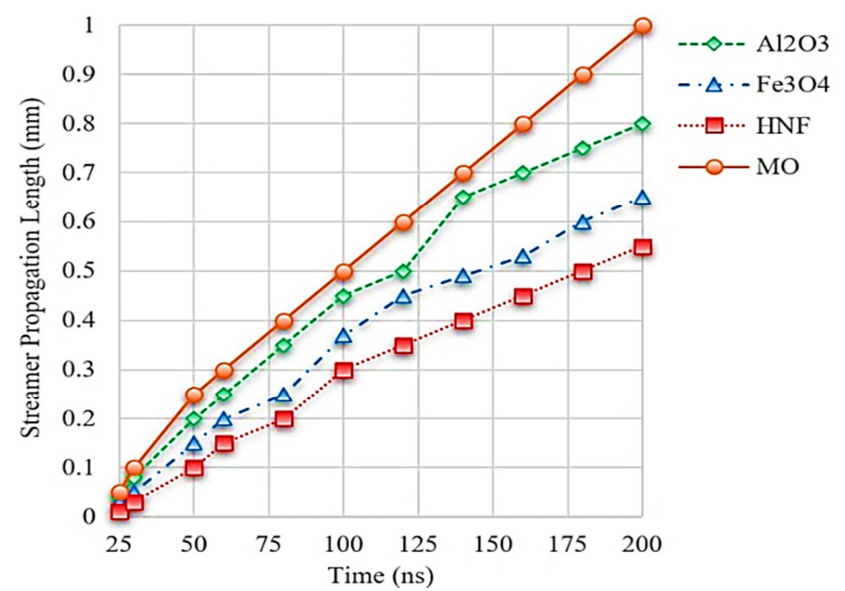

(a) Comparison of positive streamer propagation length

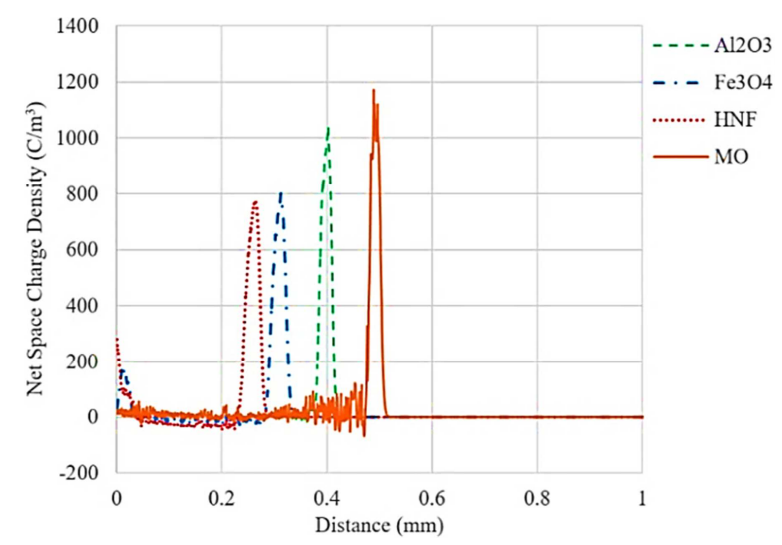

(c) Comparison of net space charge density at $100 \mathrm{~ns}$

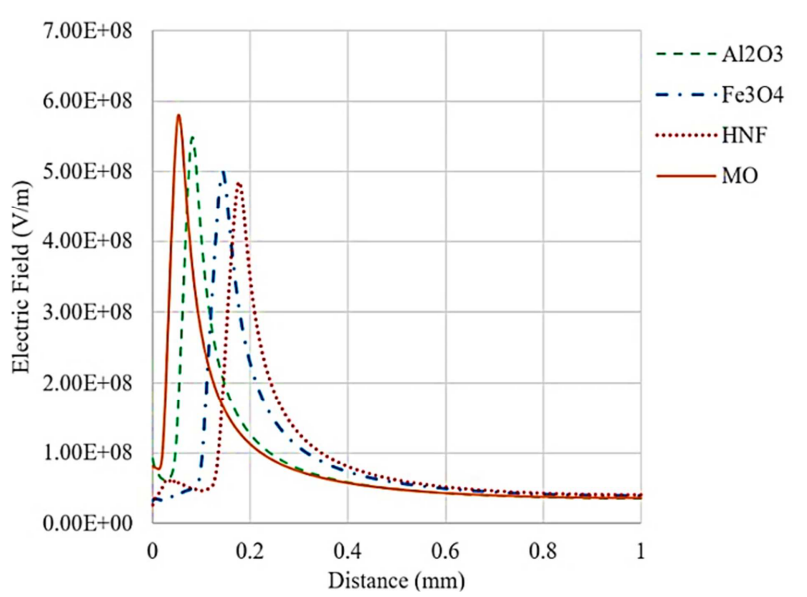

(b) Comparison of electric field strength at $30 \mathrm{~ns}$

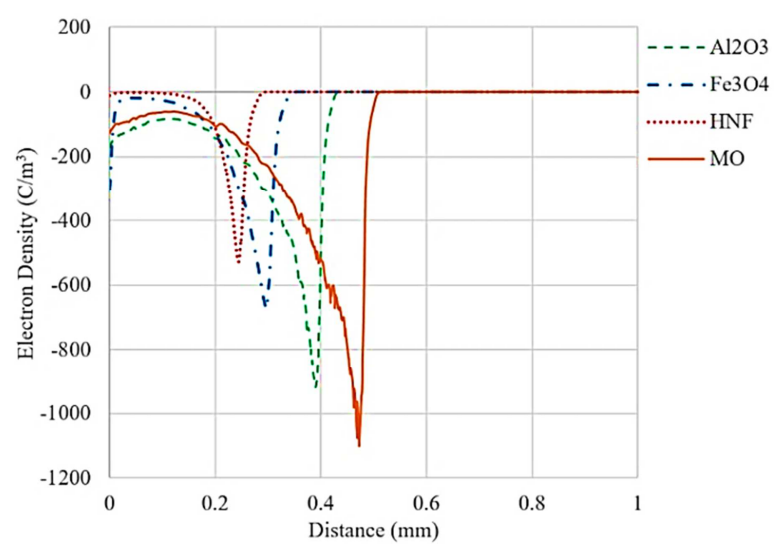

(d) Comparison of electron density at $100 \mathrm{~ns}$

Fig. 4 Impact of mono- and multi-NPs on streamer dynamics

Figs. 4(c)-(d) compare the magnitude of net space charge density and electron density available in pure oil and modified oil. It is noticed that both net space charge density and the electron density are very low in HNF compared to the pure oil and the fluid containing INPs. This is attributed to the electron trapping behavior of NPs.

Fig. 5 shows the spatial distribution of electron density at different time intervals for NFs prepared by INPs and MNPs. It is clearly seen that the NF with MNPs can absorb more electrons from the ionization phase compared to SNFs. It is worth noting that the negative electrons are absorbed until NPs are saturated. After the point of saturation, the density of the electrons starts increasing. Needless to say, the MNPs can effectively decrease the ionizable species which in turn reduce the net space charge density (as shown in Fig. 6). The streamer avalanche disappears due to low availability of space charges that is required to maintain the electric field intensity at the head of the streamer in HNFs. 


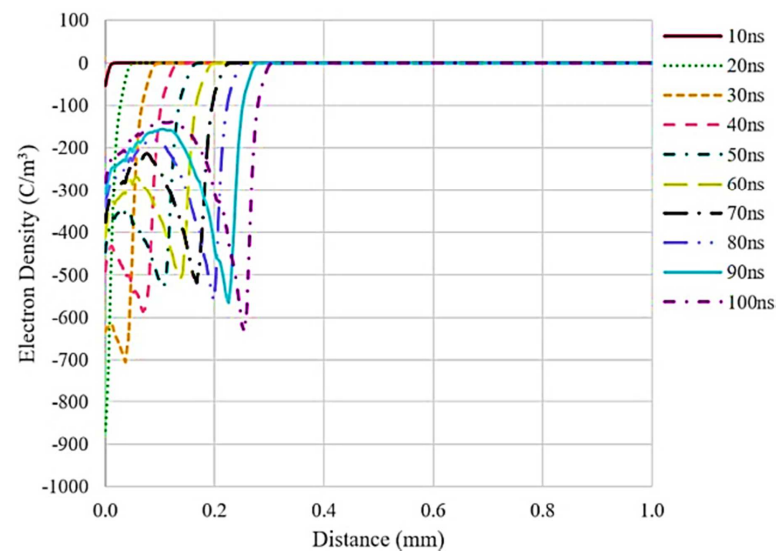

(a) $\mathrm{Al}_{2} \mathrm{O}_{3}$ based $\mathrm{NDF}$

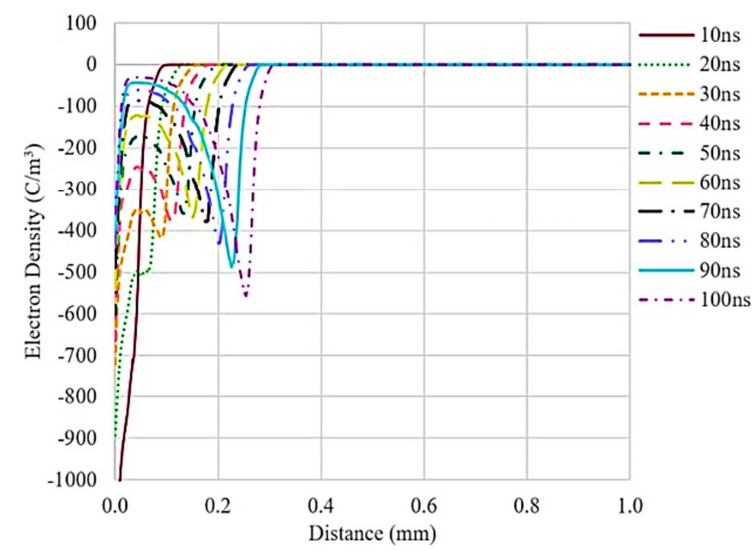

(b) $\mathrm{Fe}_{3} \mathrm{O}_{4}$ based NDF

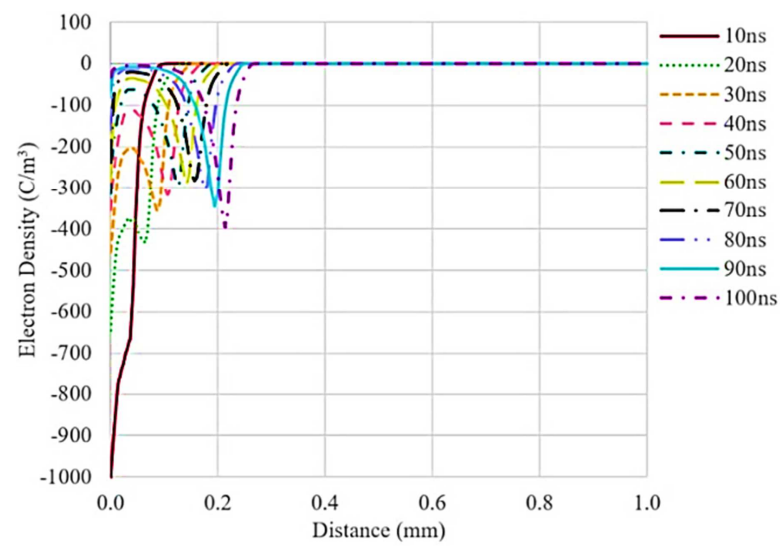

(c) $\mathrm{Fe}_{3} \mathrm{O}_{4}+\mathrm{Al}_{2} \mathrm{O}_{3}$ based $\mathrm{HNF}$

Fig. 5 Spatial distribution of electron density at different times in SNFs and HNF

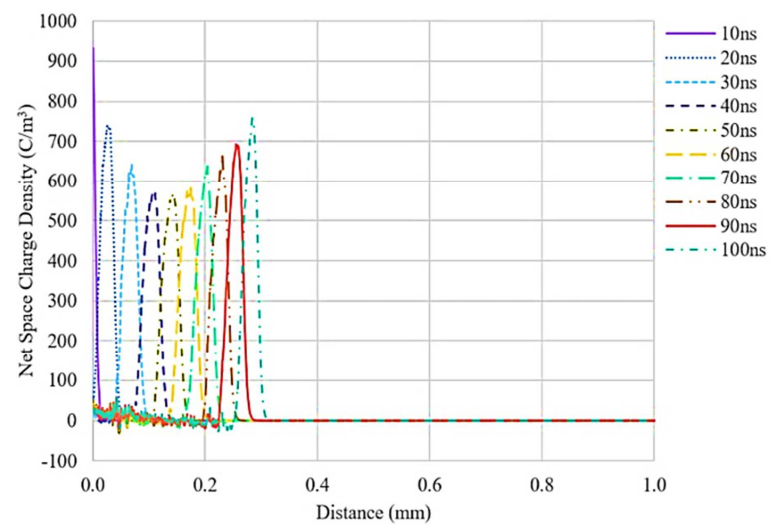

(a) $\mathrm{Al}_{2} \mathrm{O}_{3}$ based NDF

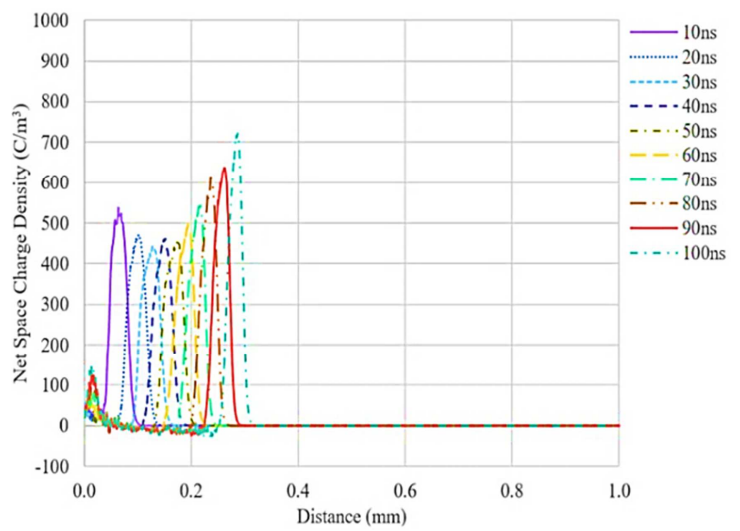

(b) $\mathrm{Fe}_{3} \mathrm{O}_{4}$ based NDF

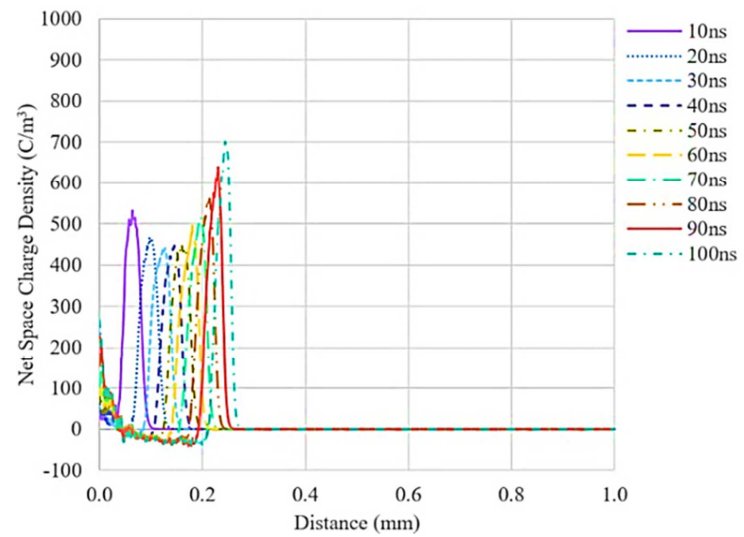

(c) $\mathrm{Fe}_{3} \mathrm{O}_{4}+\mathrm{Al}_{2} \mathrm{O}_{3}$ based $\mathrm{HNF}$

Fig. 6 Spatial distribution of space charge density at different times in SNFs and HNF 


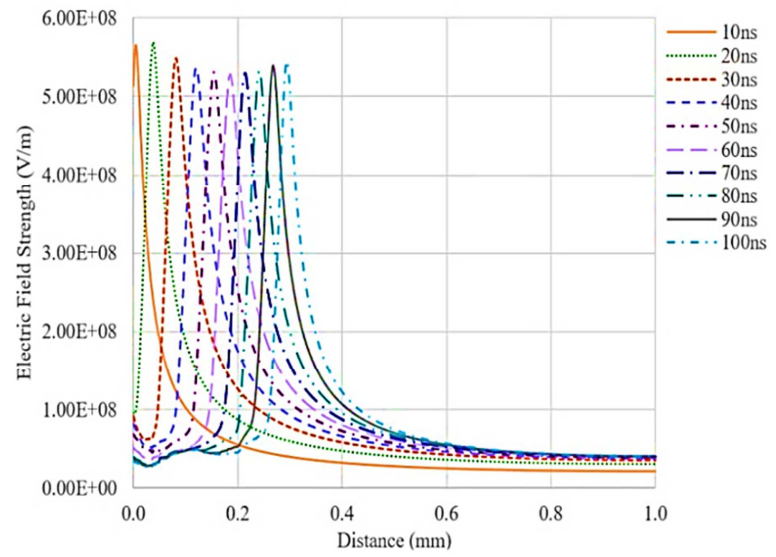

(a) $\mathrm{Al}_{2} \mathrm{O}_{3}$ based NDF

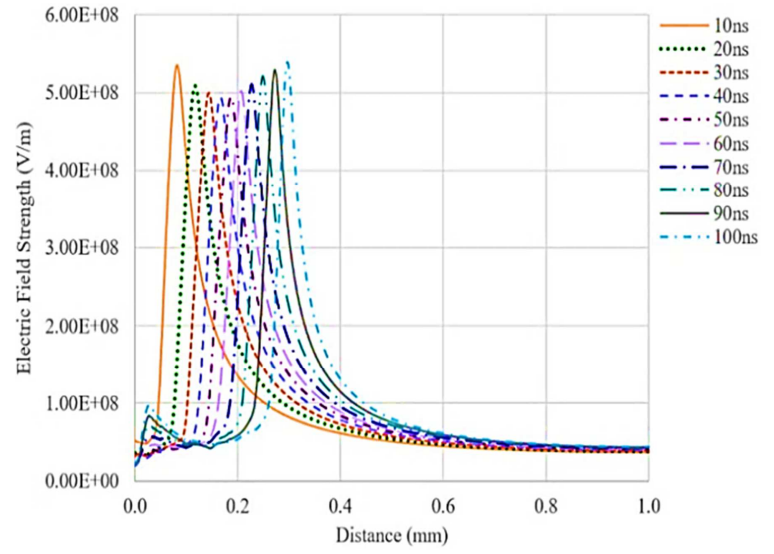

(b) $\mathrm{Fe}_{3} \mathrm{O}_{4}$ based NDF

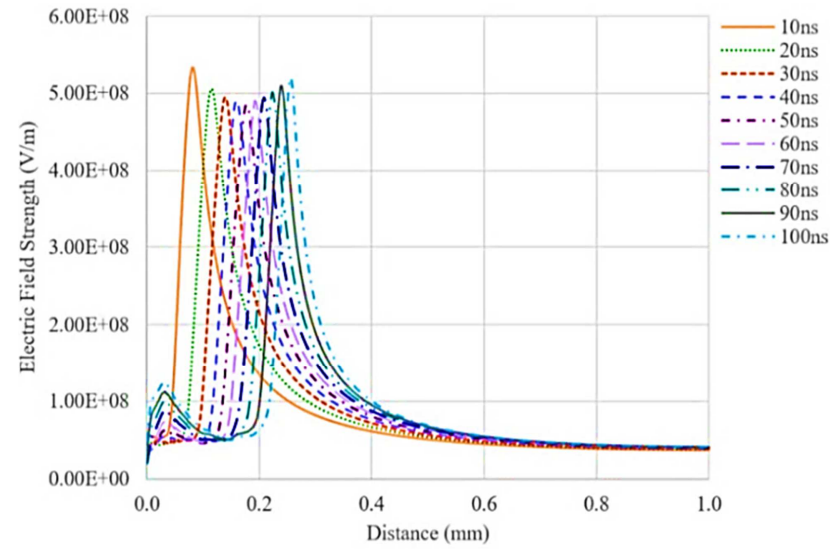

(c) $\mathrm{Fe}_{3} \mathrm{O}_{4}+\mathrm{Al}_{2} \mathrm{O}_{3}$ based $\mathrm{HNF}$

Fig. 7 Spatial distribution of electric field strength at different times in SNFs and HNF

Fig. 7 shows the spatial distribution of electric field along the symmetric axis for the $\mathrm{Nfs}$ containing $\mathrm{Fe}_{3} \mathrm{O}_{4}$ and $\mathrm{Al}_{2} \mathrm{O}_{3} \mathrm{NPs}$ as an individual and as a blend form. The obtained results are similar to that obtained in [12]. It is noticed that the electron trapping behavior of NPs can effectively reduce the magnitude of the electric field at the head of the streamer until the NPs are saturated. After the saturation, the electric field is enhanced and accelerates the further ionization due to the liberation of more electrons. Promising augmentation is observed for the fluid containing MNPs.

\section{Conclusions}

In this study, three different types of TO based NDFs with individual and mixture of $\mathrm{Fe}_{3} \mathrm{O}_{4}$ and $\mathrm{Al}_{2} \mathrm{O}_{3} \mathrm{NPs}$ were investigated numerically. The dispersion of dissimilar NPs effectively changes the streamer dynamics. From the analysis, the following observations are made:

(1) The time in which the NPs can absorb the electrons from the ionized space is known as the charging time constant. A dispersion of two or more NPs allows more electrons to be captured until they get saturated. The more the electrons are absorbed, the less the ionizable species in the liquid will be. This will reduce the electric field strength, electron density, and the net space charge density. All of these reduce the streamer growth rate and augment the DS.

(2) A mixture of magnetite and aluminum oxide NPs significantly reduce the streamer propagation length (streamer velocity) compared to both MO and SNFs. Approximately 50\%, 17\%, and 37.5\% of reduction in propagation velocity of streamer have been observed for the fluid modified by a MNPs compared to pure oil, $\mathrm{Fe}_{3} \mathrm{O}_{4}$ based NDFs, and $\mathrm{Al}_{2} \mathrm{O}_{3}$ based NDFs respectively.

(3) The dispersion of INPs with higher concentration may lead to the agglomeration that tends to reduce the dielectric properties due to the improved electrical conductivity. Dissimilar NPs disperse well at low concentrations, allowing them to avoid aggregation and increase the DS. 
(4) Both charge relaxation and polarization theories can be applied to the fluid containing a mixture of conducting and insulating NPs, but no such mechanisms were reported for the composite NPs. Needless to say, the multi-NP methodology can provide the promising augmentation in both thermal and electrical properties of carrier oil. Still it needs tremendous efforts in investigating the influence of dissimilar concentrations, shapes, and sizes of two or more NPs on both thermal and electrical properties of HNFs experimentally and numerically.

Electrical conductivity, permittivity, concentration, size, and shape of NPs play a significant role in modifying the streamer dynamics in any NP based TO. Based on the streamer simulation results, our current research focuses on the influence of MNPs with different volume fraction and charging time constants on streamer dynamics.

\section{Abbreviations and Symbols}

\begin{tabular}{|c|c|c|c|}
\hline MO & Mineral oil & $\varepsilon_{1}$ & Permittivity of TO \\
\hline TO & Transformer oil & $w_{\text {oil }}$ & Weight of TO \\
\hline $\mathrm{NF}$ & Nanofluid & $\rho_{\text {oil }}$ & Density of TO \\
\hline NP & Nanoparticle & $\vec{v}$ & Velocity of TO \\
\hline INP & Individual nanoparticle & $\vec{J}$ & Current density \\
\hline MNP & Multiple nanoparticle & $k$ & Total number of used NPs \\
\hline HNP & Hybrid nanoparticle & $m$ & Total number of conductive NPs \\
\hline NDF & Nanodielectric fluid & $R_{n}$ & Radius of conductive NPs \\
\hline SNF & Single nanoparticle based nanofluid & $R_{j+1}$ & Radius of dielectric or semi-conductive NPs \\
\hline HNF & Hybrid nanofluid & $\varepsilon_{n+1}$ & Relative permittivity of dielectric or semi-conductive NPs \\
\hline $\mathrm{XRD}$ & X-ray diffraction & $\mu_{p}, \mu_{e}, \mu_{n}$ & Mobilities of positive ion, electron, and negative ion \\
\hline TEM & Transmission electron microscope & $\mu_{n p 1}, \mu_{n p 2}$ & Mobilities of $\mathrm{Fe}_{3} \mathrm{O}_{4}$ and $\mathrm{Al}_{2} \mathrm{O}_{3}$ NPs \\
\hline SEM & Scanning electron microscope & $\rho_{p}, \rho_{e}, \rho_{n}$ & Densities of positive ion, electron, and negative ion \\
\hline DS & Dielectric strength & $\rho_{n p 1}, \rho_{n p 2}$ & Densities of $\mathrm{Fe}_{3} \mathrm{O}_{4}$ and $\mathrm{Al}_{2} \mathrm{O}_{3} \mathrm{NPs}$ \\
\hline BDV & Breakdown voltage & $\rho_{\text {npsat } 1}, \rho_{\text {npsat } 2}$ & Saturation charge densities of $\mathrm{Fe}_{3} \mathrm{O}_{4}$ and $\mathrm{Al}_{2} \mathrm{O}_{3} \mathrm{NPs}$ \\
\hline ICCD & Intensified charge coupled device & 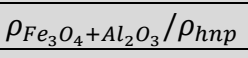 & Density of HNPs \\
\hline $\mathrm{Fe}_{3} \mathrm{O}_{4}$ & Magnetite/iron oxide & $\rho_{\text {hnf }}$ & Density of HNF \\
\hline $\mathrm{Fe}_{2} \mathrm{O}_{3}$ & Ferric oxide/iron (III) oxide & $W_{\mathrm{Fe}_{3} \mathrm{O}_{4}+\mathrm{Al}_{2} \mathrm{O}_{3}}$ & Weight of HNPs \\
\hline $\mathrm{ZnO}$ & Zinc oxide & $\tau_{n p 1}, \tau_{n p 2}$ & Charge relaxation time constants of $\mathrm{Fe}_{3} \mathrm{O}_{4}$ and $\mathrm{Al}_{2} \mathrm{O}_{3} \mathrm{NPs}$ \\
\hline $\mathrm{SiC}$ & Silicon carbide & $k_{s n f}, k_{h n f}$ & Thermal conductivities of SNF and HNF \\
\hline $\mathrm{TiO}_{2}$ & Titanium dioxide/titania & $G_{I}(|\vec{E}|)$ & Molecular ionization charge density source term \\
\hline $\mathrm{CuO}$ & Copper (II) oxide & 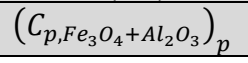 & Specific heat capacity of HNPs \\
\hline $\mathrm{Cu}_{2} \mathrm{O}$ & Dicopper oxide & & \\
\hline $\mathrm{CdS}$ & Cadmium sulfide & & \\
\hline $\mathrm{Al}_{2} \mathrm{O}_{3}$ & Aluminum oxide/alumina & & \\
\hline $\mathrm{SiO}_{2}$ & Silicon dioxide/silica & & \\
\hline $\mathrm{BN}$ & Boron nitride & & \\
\hline
\end{tabular}

\section{Conflicts of Interest}

The authors declare no conflict of interest.

\section{References}

[1] M. Rafiq, M. Shafique, A. Anam, and M. Ateeq, "Transformer Oil-Based Nanofluid: The Application of Nanomaterials on Thermal, Electrical and Physicochemical Properties of Liquid Insulation-A Review,” Ain Shams Engineering Journal, vol. 12, no. 1, pp. 555-576, March 2021.

[2] S. N. Suhaimi, A. R. A. Rahman, M. F. Din, M. Z. Hassan, M. T. Ishak, and M. T. B. Jusoh, “A Review on Oil-Based Nanofluid as Next-Generation Insulation for Transformer Application,” Journal of Nanomaterials, vol. 2020, 2061343, February 2020. 
[3] Y. Zhou, S. Sui, J. Li, Z. Ouyang, Y. Lv, C. Li, et al., "The Effects of Shallow Traps on the Positive Streamer Electrodynamics in Transformer Oil Based Nanofluids," Journal of Physics D: Applied Physics, vol. 51, no. 10, 105304, March 2018.

[4] T. Gul, A. Khan, M. Bilal, N. A. Alreshidi, S. Mukhtar, Z. Shah, et al., "Magnetic Dipole Impact on the Hybrid Nanofluid Flow Over an Extending Surface," Scientific Reports, vol. 10, 8474, May 2020.

[5] A. Sajeeb and P. K. Rajendrakumar, "Investigation on the Rheological Behavior of Coconut Oil Based $\mathrm{Hybrid} \mathrm{CeO}_{2} / \mathrm{Cuo}$ Nanolubricants," Proceedings of the Institution of Mechanical Engineers, Part J: Journal of Engineering Tribology, vol. 233, no. 1, pp. 170-177, January 2019.

[6] C. Chen, M. Niu, L. Wang, Y. Ge, M. Huang, Y. Lv, et al., "Effect of Nanoparticle Type on Prebreakdown and Breakdown Characteristics of Transformer Oil," 2nd International Conference on Dielectrics, pp. 1-4, July 2018.

[7] W. Sima, J. Shi, Q. Yang, S. Huang, and X. Cao, "Effects of Conductivity and Permittivity of Nanoparticle on Transformer Oil Insulation Performance: Experiment and Theory," IEEE Transactions on Dielectrics and Electrical Insulation, vol. 22, no. 1, pp. 380-390, February 2015.

[8] Q. Wang, M. Rafiq, Y. Lv, C. Li, and K. Yi, "Preparation of Three Types of Transformer Oil-Based Nanofluids and Comparative Study on the Effect of Nanoparticle Concentrations on Insulating Property of Transformer Oil," Journal of Nanotechnology, vol. 2016, pp. 1-6, 2016.

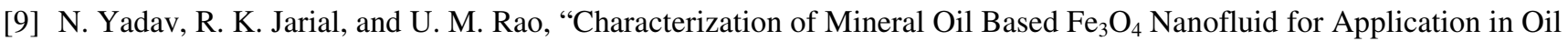
Filled Transformers," International Journal on Electrical Engineering and Informatics, vol. 10, no. 2, pp. 338-349, June 2018.

[10] J. Rodríguez-Serna, R. Albarracin-Sánchez, J. Velasco, R. Frascella, and V. A. Primo, "Streamer Simulation in Nano-Based Dielectric Fluids at Different $\mathrm{Fe}_{3} \mathrm{O}_{4}$ Nanoparticle Concentrations," 20th International Conference on Dielectric Liquids, pp. 1-4, June 2019.

[11] J. Velasco, R. Frascella, R. Albarracin, J. C. Burgos, M. Dong, M. Ren, et al., "Comparison of Positive Streamers in Liquid Dielectrics with and without Nanoparticles Simulated with Finite-Element Software,” Energies, vol. 11, no. 2, 361, February 2018.

[12] F. M. O’Sullivan, "A Model for the Initiation and Propagation of Electrical Streamers in Transformer Oil and Transformer Oil Based Nanofluids," Ph.D. dissertation, Department of Electrical Engineering and Computer Science, Massachusetts Institute of Technology, Cambridge, MA, 2007.

[13] J. G. Hwang, F. O’Sullivan, M. Zahn, O. Hjorstam, L. A. Pettersson, and R. Liu, "Modeling of Streamer Propagation in Transformer Oil-Based Nanofluids," Annual Report Conference on Electrical Insulation Dielectric Phenomena, pp. 361-366, January 2008.

[14] M. Aljure, M. Becerra, and M. Karlsson, "Streamer Inception from Ultra-Sharp Needles in Mineral Oil Based Nanofluids," Energies, vol. 11, no. 8, 2064, August 2018.

[15] R. Ekiciler, K. Arslan, O. Turgut, and B. Kurşun, "Effect of Hybrid Nanofluid on Heat Transfer Performance of Parabolic Trough Solar Collector Receiver,” Journal of Thermal Analysis and Calorimetry, vol. 143, no. 2, pp. 1637-1654, January 2021.

[16] R. Ekiciler, "Effects of Novel Hybrid Nanofluid $\left(\mathrm{TiO}_{2}-\mathrm{Cu} / \mathrm{EG}\right)$ and Geometrical Parameters of Triangular Rib Mounted in a Duct on Heat Transfer and Flow Characteristics," Journal of Thermal Analysis and Calorimetry, vol. 143, no. 2, pp. 1371-1387, January 2021.

[17] S. Sumathi, R. Rajesh, and P. Subburaj, "Investigation of Dielectric Strength of Transformer Oil Based on Hybrid $\mathrm{TiO}_{2} / \mathrm{Al}_{2} \mathrm{O}_{3} / \mathrm{MoS}_{2}$ Nanofluid Using Taguchi and Response Surface Methodology," IETE Journal of Research, in press.

[18] S. Ghadikolaei, M. Yassari, H. Sadeghi, K. Hosseinzadeh, and D. D. Ganji, "Investigation on Thermophysical Properties of $\mathrm{TiO}_{2}-\mathrm{Cu} / \mathrm{H}_{2} \mathrm{O}$ Hybrid Nanofluid Transport Dependent on Shape Factor in MHD Stagnation Point Flow," Powder Technology, vol. 322, pp. 428-438, December 2017.

[19] S. Aberoumand and A. Jafarimoghaddam, "Tungsten (III) Oxide $\left(\mathrm{WO}_{3}\right)$-Silver/Transformer Oil Hybrid Nanofluid: Preparation, Stability, Thermal Conductivity and Dielectric Strength,” Alexandria Engineering Journal, vo. 57, no. 1, pp. 169-174, March 2018.

[20] A. Thabet, M. Allam, and S. Shaaban, “Assessment of Individual and Multiple Nanoparticles on Electrical Insulation of Power Transformers Nanofluids,” Electric Power Components and Systems, vol. 47, no. 4-5, pp. 420-430, May 2019.

[21] A. Thabet, M. Allam, and S. Shaaban, "Investigation on Enhancing Breakdown Voltages of Transformer Oil Nanofluids Using Multi-Nanoparticles Technique," IET Generation, Transmission, and Distribution, vol. 12, no. 5, pp. 1171-1176, March 2018. 
[22] S. H. Qing, W. Rashmi, M. Khalid, T. C. S. M. Gupta, M. Nabipoor, and M. T. Hajibeigy, "Thermal Conductivity and Electrical Properties of Hybrid $\mathrm{SiO}_{2}$-Graphene Naphthenic Mineral Oil Nanofluid as Potential Transformer Oil," Materials Research Express, vol. 4, no. 1, 015504, January 2017.

[23] D. E. A. Mansour, E. M. Shaalan, S. A. Ward, A. Z. E. Dein, H. S. Karaman, and H. M. Ahmed, "Multiple Nanoparticles for Improvement of Thermal and Dielectric Properties of Oil Nanofluids," IET Science, Measurement, and Technology, vol. 13, no. 7, pp. 968-974, September 2019.

[24] D. E. A. Mansour, E. A. Shaalan, S. A. Ward, A. Z. E. Dein, and H. S. Karaman, "Multiple Nanoparticles for Enhancing Breakdown Strength and Heat Transfer Coefficient of Oil Nanofluids," 19th International Middle East Power Systems Conference, pp. 1406-1410, December 2017.

[25] A. Thabet, M. Allam, and S. Shaaban, "Slowing Positive Streamer Propagation in Silicon and Ester Transformer Oil Using Multi-Nanoparticles Technique,” International Journal of Applied Energy Systems, vol. 1, no. 1, pp. 15-20, January 2019.

[26] D. Amin, R. Walvekar, M. Khalid, M. Vaka, N. M. Mubarak, and T. C. S. M. Gupta, "Recent Progress and Challenges in Transformer Oil Nanofluid Development: A Review on Thermal and Electrical Properties,” IEEE Access, vol. 7, pp. 151422-151438, 2019.

[27] L. S. Sundar, K. V. Sharma, M. K. Singh, and A. C. M. Sousa, "Hybrid Nanofluids Preparation, Thermal Properties, Heat Transfer and Friction Factor-A Review,” Renewable and Sustainable Energy Reviews, vol. 68, part 1, pp. 185-198, February 2017.

[28] S. Mourdikoudis, R. M. Pallares, and N. T. Thanh, "Characterization Techniques for Nanoparticles: Comparison and Complementarity upon Studying Nanoparticles Properties,” Nanoscale, vol. 10, no. 27, pp. 12871-12934, July 2018.

[29] High-Voltage Test Techniques_-Part 1: General Definitions and Test Requirements, IEC Standard 60060-1, 2010.

Copyright $\odot$ by the authors. Licensee TAETI, Taiwan. This article is an open access article distributed under the terms and conditions of the Creative Commons Attribution (CC BY-NC) license (https://creativecommons.org/licenses/by-nc/4.0/). 